\title{
THE URBAN ENVIRONMENTAL TRANSITION: SOME REFLECTIONS ON THE USE OF VEGETATION TO MONITOR URBAN ENVIRONMENTAL QUALITY
}

\author{
Rohinton Emmanuel
}

Urban planning and design action in the face of rapid global urbanization and attendant changes in the urban environment urgently needs holistic indices of environmental quality. The use of vegetation changes to monitor urban environmental quality appears promising, thanks to recent advances in the remote sensing of greenery. The utility of remotely sensed vegetation data to monitor the urban physical environment is well known. Recently, Emmanuel (1997) demonstrated that such data could also mirror the social and demographic trends in cities.

This paper explores the urban design/planning implications of using vegetation change as indicator of urban environmental trends. The case study is based on research work carried out in Detroit, USA, where urban decay in recent years has lead to significant greening in the heart of the city. A hypothesis of urban environmental transition is proposed.

\subsection{INTRODUCTION}

It is well recognized that global urbanization has rapidly intensified in recent years. By the turn of the next century, global urban population is expected to outnumber the rural population (Oke, et al., 1991). This trend is both new and unprecedentêd in human history. It is new in that only in the recent past that global urbanization has intensified. Earlier episodes of urbanization were confined only to certain areas of the world (for example, Europe and the North America after the industrial revolution). During the last 150 years, the global urban population has increased from a mere $3 \%$ in the 1850s (Detwyler \& Marcus, 1972) to more than 45\% in 1995 (World Resources, 1996). While the global population has increased six times during the last two hundred years, urban population has grown 128 times (cf. Schell, et al., 1993).

The changes caused by urbanization are unprecedented because humankind has no previous experience with such rapid transformation. Even though the global population growth rates seem to abate somewhat, global urbanization shows no sign of retreat (cf. World Urbanization Prospects, 1990).
The rapid global urbanization has brought in its wake many hitherto unknown changes to humans, other life forms and the physical environment. Changes caused by urbanization on humans include diseases asssociated with crowding (tuberculosis, pneumonia, respiratory illnesses, measles, common cold, etc. (Rose, 1976; Jauregui, 1986; Weihe, 1986); air pollution-related illnesses and psychological and emotional disorders (Carruthers, 1976; Harrison \& Gibson, 1976; Rose, 1976; Lake, et al., 1993). Urban effects on other life forms include, physiological changes in urban flora and fauna and their diversity (Sukopp \& Werner, 1982) and disease and growth retardation in vegetation (Stulpnagel, Horbert \& Sukopp, 1990). On the physical environment, the changes associated with air, water quality degradation (Urban Air Pollution, 1992) and microclimate changes (cf. Oke, 1987) come to mind.

In view of. the rapidity and the unprecedented nature of these events, there is a great need to monitor and model the changes brought about by urbanization. This will help predict future patterns of environmental changes and to control their negative impacts upon humans, other life forms and the physical environment. To be of use to urban designers and policy makers, the 
indicators must monitor changes in both the physical and the social environment.

The monitoring of changes in urban vegetation can provide such a holistic indication to the urban environmental quality. Vegetation changes in urban areas both mirrors and is influenced by human action in cities. The amount of vegetation in cities is heavily affected by humans (decrease in vegetation due to deforestation as well as increase in urban vegetation due to tree planting campaigns, home gardening, etc.). The environmental changes effected by human action also influences the quality of urban vegetation. Monitoring this two-way interaction has become inexpensive in recent years, thanks to developments in the remote sensing field.

A previous paper by the author (Emmanuel, 1997) has shown the feasibility of using urban vegetation changes to monitor social and demographic changes in Detroit. It is in this light that the present paper explores the urban planning and design implications of using vegetation change as indicator of urban social and physical quality of life. It also shows the environmental consequences of inadvertent greening in the city. Lessons for post-industrial cities like Detroit as well as newly industrializing ones are explored. The paper posits the hypothesis that urban environmental changes involve several phases, and each calls for spatially and temporally distinctive planning strategies.

\subsection{VEGETATION AS AN ENVIRONMENT MONITOR: BACKGROUND}

There is a large volume of vegetation in cities, particularly in the tropics, and the effects on the urban environment are usually positive. Urban vegetation brings about cooling (Oke, 1989; Parker, 1982), reduces surface water run-off (Rutter, 1972; Shuttleworth, 1989), improves thermal comfort of urban dwellers (Stark \& Miller, 1977; Taha, et al., 1987) and adds to their psychological well being (Ames, 1980; Ulrich,1984; Willeke, 1989).

Workers have also recognized that the environment/vegetation dynamic is a twoway cyclical process. The additional stresses associated with urban environment (thermal and air quality stresses) usually impinge negatively upon the health of urban vegetation. (Sukopp \& Werner, 1982, Stulpnagel, et al., 1990).

This two-way interaction between vegetation and environment enable urban vegetation to be an indicator of the environmental quality of its surroundings. Evidence for use of vegetation as an urban environment monitor include: the monitoring of air quality - Novak \& McBride (1993), Mishra, et al., (1994), Sloof (1995); air temperature monitoring - Gallo, et al., (1993), Suzuki, et al. (1993), Nichol (1994); surface temperature - Kawashima (1994); demographic and social changes - Emmanuel (1997).

\subsection{VEGETATION CHANGES IN DETROIT: SUMMARY OF FINDINGS}

A thematic comparison of two LANDSAT satellite images taken over Detroit in the autumns of 1975 and 1992 revealed a greening trend in the heart of the city (Nystuen, et al., 1995). It is well known that urban decay has long been the trend in Detroit, resulting in large tracts of vacant land in the central city area (Bruhn \& Brahn, 1990). However, the associated greening makes Detroit unique among the world's urban centers for two reasons.

1. Detroit has gone through the full cycle of urban demographic change (establishment as a small trade post, relatively slow growth, a period of rapid and chaotic change, decline in population and eventual abandonment of parts of the city). As such, it offers lessons for cities yet to go through the full cycle of urban transitions;

2. The planning implications of vegetation monitoring in Detroit may form the basis of a theory of urban environmental transition.

In order to quantify the greenness changes in Detroit, a "Greenness Change Index" (GCI) was developed for each neighborhood in the city. The development of GCI involved counting the number of 


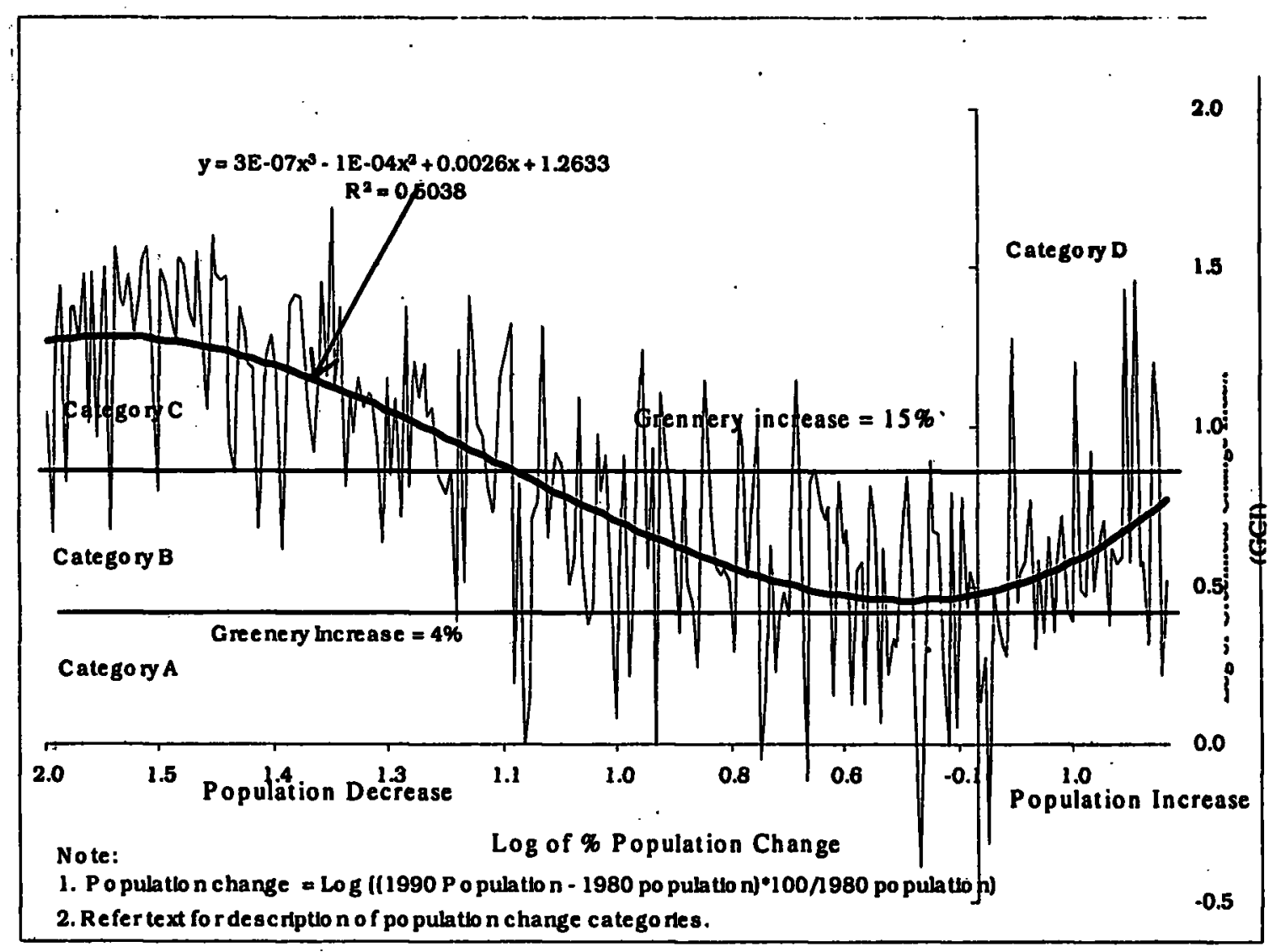

Figure 1 Relationship between population and vegetation changes in Detroit

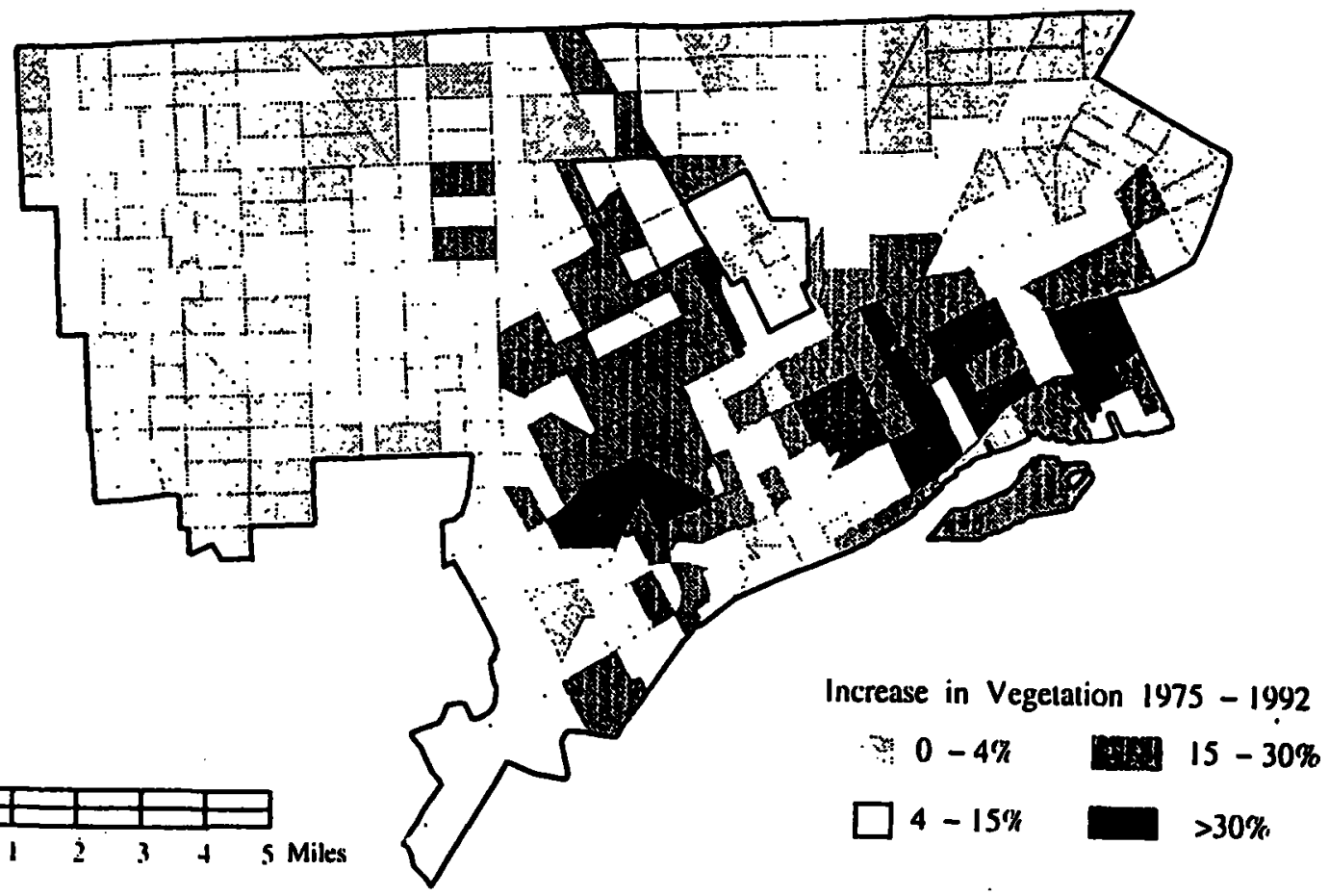

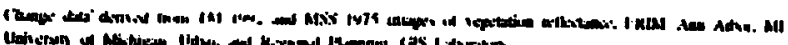

Figure 2 Spatial distribution of greening trends in Detroit 
pixels showing increase in greenness between 1975 and 1992 and dividing it by the total number of pixels in that neighborhood. A pixel refers to a ground area of $30 \mathrm{~m}$ by $30 \mathrm{~m}$. The amount of greenness per pixel was computed on the basis of the spectral reflectance in the near infra-red (NIR) and the visible bands, using a data transformation procedure called "tasseled cap transformation". The calculation of greenness change employed a "change vector analysis". Emmanuel (1997) gives detailed description of these procedures and shows a color image of vegetation changes in Detroit between 1975 to 1992.

Figure 1 shows the relationship between population change and greenness change averaged per neighborhood in Detroit. There seems to be four distinctive sections to this relationship.

Category A - Population decreases somewhat, and greenness increases slightly.

Category B - Population decreases moderately and greenness increase is linear, with a moderate slope.

Category C - Population decreases drastically, greenness change reaches its peak.

Category D - Population increases somewhat, and greenness changes are mixed.

Since most of the neighborhoods showed mixed areas of greenness increase and decrease, it was necessary to differentiate tracts that are predominantly greening from those that are predominantly losing vegetation. This was achieved by comparing the amount of greenness decline (red pixels in Figure 2, Emmanuel, 1997) with the amount of greenness increase (green pixels in the same image) in each area. Figure 2 shows the census tracts classified into three categories:

Greenness Change $>15 \% \quad$--

Overall increase in greenness.

Greenness Change $<4 \% \quad$--Overall reduction in greenness.
$4 \%<$ Greenness Change $<15 \%$--

Transitional zone

A pattern of concentric circles centered on the downtown is clearly visible in Figure 2. A ring of area furthest from city center shows reduction in greenness while the city center exhibits an increase in greenness. The area in-between the two forms a semi-circle of transitional zone.

Selected neighborhoods in each of the three zones were visited by the author to ascertain the ground conditions. Areas with an overall increase in greenness ( $\mathrm{GCI}>15 \%)$ showed advanced urban decay (boarded up building, burned down houses, overgrown lots, etc.). Areas with an overall decrease in greenness (GCI < 4\%) appeared the most vibrant (intact neighborhoods) while the transitional zone showed early signs of decay (a mix of intact and decaying neighborhoods).

It is hypothesized that the transitional zone $(4 \%<\mathrm{GCI}<15 \%)$ is the area most in need of planners' attention. If no active intervention measures are introduced, this zone could continue to deteriorate and become similar to the devastated areas in the inner city.

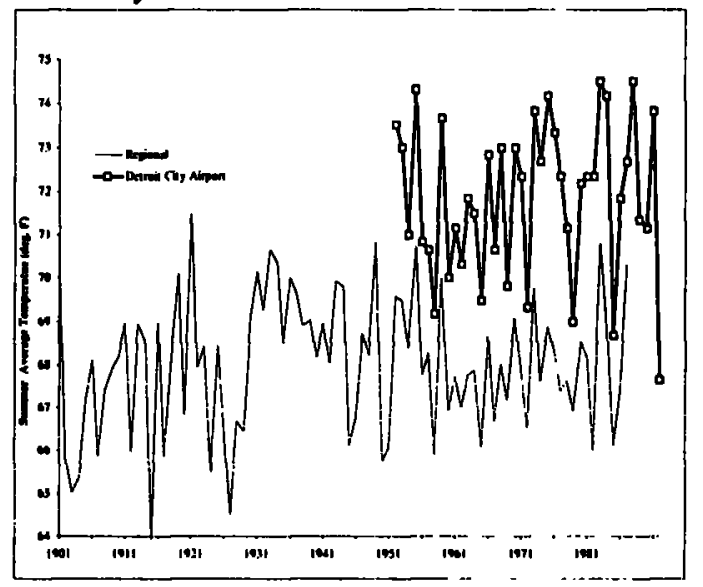

Figure 3 Average summer nighttime air temperature comparison between Detroit

\subsection{VEGETATION CHANGES AND THE PHYSICAL ENVIRONMENT IN DETROIT}

While the social environmental condition seems depressing, positive physical environmental trends were also recorded in Detroit. Figure 3 shows minimum (nighttime) air temperature trend during summer 
months (June, July and August) in Detroit in comparison with that in the Great Lakes region (the state of Michigan and the lake shore regions of Illinois, Indiana, Ohio, Minnesota and Wisconsin; Karl, et al., 1990). While the regional average has stabilized after mid 1920s, Detroit's temperature has continued to drop. That city temperature continues to be higher than the regional average indicates the presence of an urban heat island in Detroit.

Figure 4 (a) \& (b) shows the dust particle (Particle Matter less than 10 microns in diameter -- $\left.\mathrm{PM}_{10}\right)$ and Sulfur dioxide $\left(\mathrm{SO}_{2}\right)$ trends in Detroit city and its vicinities. Here too, improvements in air quality at the city center are evident in recent years.

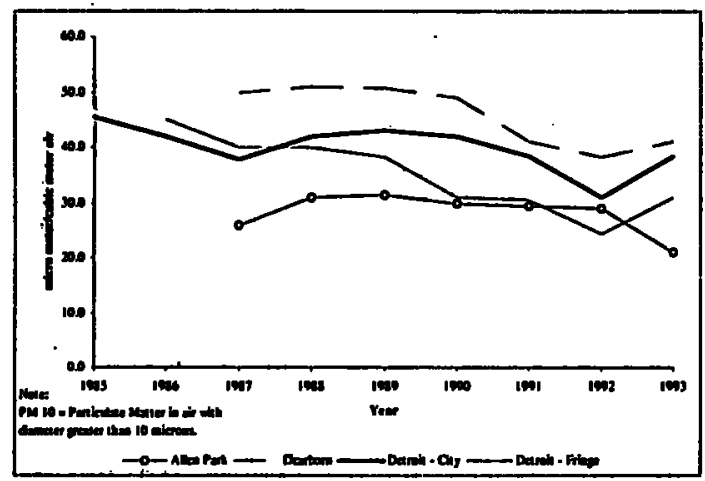

Figure 4(a) PM10 distributions in Detroit and suburbs

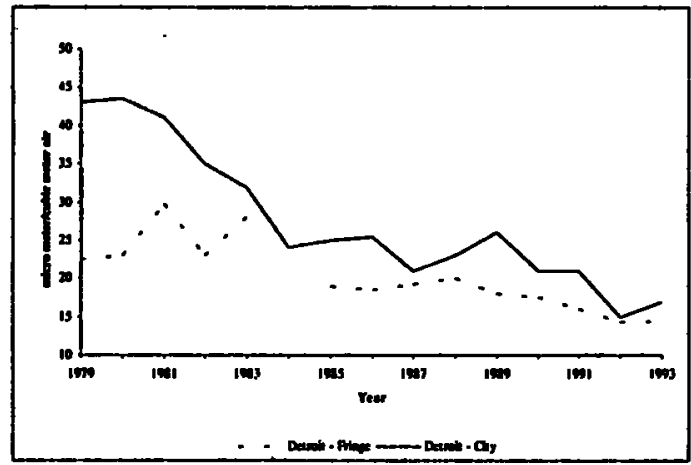

Figure 4(b) $\mathrm{SO}_{2}$ distribution in Detroit

City and the region

It therefore appears that some of the urban physical environmental changes associated with urbanization may be reversible. The decline in industrial activity, population and the use of automobiles may set limits to urban physical environmental changes. Negative changes to the physical environment of Detroit and cities that are at a similar stage in their demographic transition may have already peaked.

Natural growth of vegetation due to neglect in Detroit is causing a decreasing trend in air temperature and improvements to air quality. A planned urban greening on the other hand, can retard environmental changes or even reverse the trends, without necessarily destroying urban life.

\subsection{URBAN ENVIRONMENTAL TRANSITION - A HYPOTHESIS}

In light of the above discussion, the current paper proposes a theory of urban environmental transition with temporally differentiated phases. The monitoring of vegetation changes simplifies the detection of these transitional phases. It is possible that urban environmental changes involve at least three temporal stages:

1. Slow growth in urbanization, barely noticeable environmental changes.

2. A greater increase in impervious urban surfaces like buildings and asphalt, increases in industrial activity, and population increase, leading to more solar heat trapping, loss of native urban vegetation and greater surface water runoff. The establishment of more alien forms of vegetation is also seen (Sukopp \& Werner, 1982; Stulpnagel et al., 1990).

3. Decrease in industrial activity, decrease in population and buildings, occurring in conjunction with mature colonies of alien forms of vegetation.

These trends may all be present at a given city albeit at different sections of the city. The monitoring of urban vegetation changes can help identify the environmental transition phase a particular neighborhood is currently undergoing. The monitoring of urban vegetation change in Detroit clearly points to such spatially distinct environmental transitions.

The classification of urban neighborhoods into early, middle or late urban environmental transition phases will benefit urban planners and others interested in creating livable cities. Such an identification will help prioritize design 
goals. For example, if a neighborhood is identified as going through the earliest stage of environmental transition, design strategies thaf regulate urban form in a climatically suitable manner (like ordinances that promote shaded street, discourage certain solar orientations, limits on building heights and setbacks, etc.) may be promoted. Those in the second stage of transition, with very little room to manipulate urban form or activities, may find legislative caps on industrial activity, mandatory air cleaning requirements, and promotion of nonpolluting modes of traffic helpful. On the other hand, areas undergoing the late stages of transition with greater urban decay, might profit from urban greening campaigns, encouragement of non-polluting urban activities and experiments with high-density, low-rise development that might bring back the necessary population density to sustain urban life with minimal destruction to nature.

A temporally differentiated transition theory of urban environmental changes can also form the basis for the development of mathematical models for each stage. Such models can be useful in predicting the future rates of change within a given environmental transition zone.

\subsection{CONCLUSIONS}

There is no doubt that urbanization will continue well into the next century. However, as cities mature, certain environmental transitions will settle in, creating their own two-way dynamism: city on environment and environment on city. Environmental changes in cities like Detroit that has gone through a full cycle of socio economic transformations offers lessons that rapidly urbanizing cities may find useful. The manner in which nature seems to have taken hold of Detroit and the associated environmental changes offers clues for the intentional exploitation of nature in cities for climate, air quality and social mitigation purposes. Urban design strategies that allow for high-density, low-rise developments, changes to urban zoning ordinances that allow for mixed land uses and intentional urban greening can help mitigate the negative impacts of urbanization upon the environment without destroying urban life.

\section{REFERENCES}

Ames, R.G., (1980). "The sociology of urban tree planting", J. Arboriculture, 6(5): 120-123.

Bruhn, M.S., \& J.F. Brahn, (1990). Survey \& recommendations regarding vacant land in the city: Report submitted to the city council of Detroit, Detroit: city planning commission, (unpublished).

Carruthers, M., (1976). "Biochemical responses to environmental stress". In, Harrison, G.A. \& J. B. Gibson, (eds.), Man in Urban Environments, Oxford: Oxford University Press, pp. 247-273.

Detwyler, T.R. \& M.G. Marcus, (1972). Urbanization and Environment: The Physical Geography of the City, Belmont; CA.: Duxbury Press.

Emmanuel, R., (1997). "Urban vegetational change as an indicator of demographic trends in cities: the case of Detroit". Environment \& Planning B, 24: 415-426.

Gallo, K.P., A.L. McNab, T.R. Karl, J.F. Brown, J.J. Hood \& J.D. Tarpley, (1993). "The use of a vegetation index for the assessment of the urban heat island effect", Int'L. J. Remote Sensing, 14(11): 2223-2230.

Harrison, G.A. \& J. B. Gibson, (eds.), (1976). Man in Urban Environments, Oxford: Oxford University Press.

Jauregui, E., (1986). "Urban climatology in the tropics", Report of First Session of CCI Working Group on Climate and Urban Areas Including Buildings and Other Aspects, WCAP-8, WMO/TD No. 287, Geneva: World Meteorological Organization, pp. 13-19.

Karl, T.R., et al., (1990). "Temperature Records Great Lakes Region". In, Boden, Thomas A., et al., (eds.), Trends 1990. Oak Ridge, TN.: Oak Ridge National Laboratory.

Kawashima, S., (1994). Relation between vegetation, surface temperature \& surface composition in the Tokyo region during winter", Remote Sensing of Environment, 50: 52-60.

Lake, J.V., G.R. Bock \& K. Ackrill. (eds.), (1993). Environmental Change and Human Health, Chichester, U.K.: WileyInterscience.

Michigan Dept. of Natural Resources, (MI DNR), (1993). Air Quality Report - 1993. Lansing, MI.: Michigan DNR.

Mishra, J.K., R. Aarathi \& M.D. Joshi, (1994). "Remote sensing quantification and change detection of natural resources ", Atmospheric Environment, 28(19):31313137. 
National Climate Data Center, (NCDC), (1994). Global Daily Summary: Temperature \& Precipitation, version 1.0 (CD-ROM). Ashville, N.C.: NCDC.

Nichol, J. E., (1994). "A GIS-based approach to microclimate monitoring in Singapore's high-rise housing estates", Photogrammetric Engineering \& Remote Sensing, 60(10): 1225 - 1232.

Novak, D.J. \& J.R. McBride, (1993). "Testing microdensitometric ability to determine Monterey Pine urban tree stress', Photogrammetric Engineering \& Remote Sensing, 59(1): 89-91.

Nystuen, J. D., R.W. Marans \& R.M. Ryzner, (1995). "Open space \& vegetation in a declining city". Paper Presented at the 37th Annual Association of Collegiate Schools of Planning ACSP 195 Conference, October 19-22. Detroit, MI.

Oke, T.R., (1987). Boundary Layer Climates, London: Methuen.

- (1989). "The micrometeorology of the urban forest", Philosophical Transactions of Royal Society of London B, 324: 335350.

Oke, T.R., R. Taesler \& L.E. Olsson, (1990/91). The Tropical urban climate experiment (TRUCE)", Energy \& Buildings, 15/16: 67-73.

Parker, J., (1982). "Do energy conserving landscape work?" Landscape Architecture, 72(4): 89-90.

Rose, G.A., (1976). "Epidemiological evidence for the effects of urban environment". In, Harrison, G.A. \& J. B. Gibson, (eds.), Man in Urban Environments, Oxford: Oxford University Press, pp. 205-216.

Rutter, A.J., (1972). Transpiration. London: Oxford University Press.

Schell, L.M., M.T. Smith \& A Billsborough, (1993). "Human biological approaches to the study of third world urbanism". In, Schell, L.M., M.T. Smith \& A. Billsborough, (eds.)., (1993). Urban Ecology \& Health in the 3rd World, Cambridge: Cambridge University Press. pp. 1-9.

Shuttleworth, W.J., (1989). "Micrometeorology of tropical \& temperate forest", Philosophical Transactions of the Royal Society of London, B, 324:299-334.

Sloof, J.E., (1995). "Lichens as quantitative biomonitors for atmospheric trace element deposition, using transplants", Atmospheric Environment, 29(1): 11-20.

Stark, T.F. \& D.R. Miller, (1977). "Effect of synthetic surfaces \& vegetation in urban areas on human energy balance \& comfort", Proceedings of a Conference on Metropolitan Physical Environment, Syracuse, NY., 25-29, Aug., 1975. USDA Forest Service Technical Report NE-25, Upper Darby, PA.: Northeastern Forest Experiment Station, pp. 139-151.

Stulpnagel, A V., M. Horbert \& H. Sukopp, (1990). "The importance of vegetation for urban climate", in, Sukopp. H., S. Hejny \& I. Kowarik, (eds.), Urban Ecology: Plant \& Plant Communities in Urban Environments. The Hague: SPB Academic Publishing Co., pp. 175-193.

Sukopp, H., \& P. Werner, (1982). Nature in Cities, Nature \& Environment Series \#28, Strasbourg: Council of Europe Publication.

Suzuki; K., K. Ohnuma \& Y. Yasuda. (1993). "Environmental monitoring by using monthly NVI data \& climate data". Proceedings of the 1993 International Geoscience \& Remote Sensing Symposium (IGARSS'93) - Better Understanding of Earth Environment, August $18-21$, Tokyo, Japan. Volume III, pp. 1149-1151.

Taha, H., H. Akbari, A. Rosenfeld \& J. Huang, (1988). "Residential cooling loads and the urban albedo - the effects of albedo", Building \& Environment, 23(4): 271-283.

Ulrich, R.S., (1984). "View through a window may influence recovery from surgery", Science 224(27 April): 420-21.

Urban Air Pollution in Megacities of the World, (1992?). New York: Blackball Reference.

Weihe, W.H., (1986). "Life expectancy in tropical climates and urbanization", in T.R. Oke, (ed), Urban Climatology and its Application with Special Regard to Tropical Areas, Publication No. 652, Geneva: World Meteorological Organization, pp. 313-353.

Willeke, D.C., (1989). "The imperative forest". In, Moll, G. \& S. Ebenreck, (eds.), Shading our Cities: A Resource Guide for Urban and Community Forests, Washington, D.C.: Island Press, pp. 58-63.

World Resource 1994-1995, (1994). New York: Oxford University Press.

World Urbanization Prospects 1990, (1991). New York, NY.: United Nations.

Dr. Rohinton Emmanuel is a Senior Lecturer in Architecture at the University of Moratuwa. This paper is based on data collected during his doctoral studies at the University of Michigan, Ann Arbor, U.S.A. 